\title{
Programa Universidade para Todos (PROUNI): efeitos financeiros em uma instituição de educação superior privada
}

\begin{abstract}
Celia Maria Haas
Rosangela da Silva Pardo

Resumo: O artigo apresenta os resultados de pesquisa finalizada em 2013, cujo propósito foi o de verificar se a isenção fiscal alcançada por uma Instituição de Educação Superior Privada com fins lucrativos, após adesão ao Programa Universidade para Todos (PROUNI), superou os investimentos em bolsas de estudos ofertadas pelo programa e, com isso, assegurou a continuidade ou, até mesmo, a expansão desta instituição no mercado educacional. A investigação, desenvolvida em duas etapas, teve, na primeira, um estudo dos documentos contábeis institucionais relativos ao Prouni. A entrevista com o mantenedor da instituição, na segunda etapa, foi realizada para qualificar as informações obtidas na análise dos documentos. Para compreensão dos dados, contou-se com as reflexões de autores que tratam do tema em estudo. Os resultados demonstraram que o ganho fiscal alcançado pela instituição, após sua adesão ao programa, foi superior aos investimentos destinados em bolsas de estudos e contribuiu financeiramente para a estabilização, manutenção e o potencial crescimento institucional nos últimos anos. Como apontam alguns autores, pôde-se apreender, com a pesquisa, que a redução fiscal foi o principal resultado positivo da adesão da IES ao programa.
\end{abstract}

Palavras-chave: Políticas públicas. Educação superior. PROUNI.

The financial effects of the Program Universidade para Todos (PROUNI) in a private university

Abstract: This research aimed at verifying the financial effects of the Universidade para Todos program (PROUNI) in a profit-seeking private university. Furthermore, it investigated to what extent the university's exemption from taxation after taking part of PROUNI outnumbered the investments in scholarships offered by the program as well as the permanence and a potential expansion of the institution in the market. The research was developed in two stages. Firstly, it was done a study of the accounting documents. Secondly, an interview with the maintainer of the private institution aimed at qualifying the information obtained during the analysis of the documents. The interpretation of data was carried out with the support of the authors who discuss the theme in the light of public finances. The outcomes demonstrated that the profits made by the institution after enrolling in the program contributed to its stabilization, maintenance and expansion in the last few years. As some authors point out, we can apprehend with this research that the fiscal reduction was the main positive result of enrolling in the program.

Key words: Public policies. Higher education. PROUNI. 
Programa Universidade para Todos (PROUNI): efeitos financeiros em uma instituição de educação superior privada

\section{Introdução}

Em 2004, no Governo de Luis Inácio Lula da Silva, foi criado o Programa Universidade Para Todos (PROUNI), por meio da Medida Provisória $\mathrm{n}^{\circ}$. 213, de 10 de setembro daquele ano (BRASIL, 2004), implementado com a edição da Lei Federal no n $^{\circ} 11.096$, de 13 de janeiro de 2005 (BRASIL, 2005), com a finalidade de concessão de bolsas de estudos, integrais e parciais, a estudantes brasileiros, sem diploma de nível superior, em cursos de graduação de instituições privadas de educação superior (BRASIL, 2004, 2005).

Para que se possa entender o contexto em que foi instituído o Programa Universidade para Todos (PROUNI), convém conhecer o cenário econômico no qual este programa está inserido. Com este propósito, apresentam-se, inicialmente, as medidas de política econômica que orientaram as finanças públicas e a questão da renúncia fiscal no Brasil, desde a década de 1960 e como esta isenção fiscal beneficiou a criação, o financiamento e a expansão das instituições privadas de educação superior, focando neste texto, os efeitos da isenção fiscal alcançada pela adesão ao Programa Universidade para Todos (PROUNI) que superam a oferta das bolsas de estudos, exigência do programa, viabilizando a manutenção e expansão de uma Instituição de Educação Superior Privada.

A política econômica baseada na renúncia fiscal que vigorou no Brasil nos anos 60 e 70 desempenhou papel central no financiamento da educação superior privada, tanto nos períodos de prosperidade econômica, como, também, de crise, garantindo a atividade das instituições educacionais privadas com incentivos fiscais.

Marco principal deste período, a Lei No 5.172, de 25 de outubro de 1966 (BRASIL, 1996), dispôs sobre o "Sistema Tributário Nacional e institui normas gerais de direito tributário aplicáveis à União, Estados e Municípios" e vedava ‘à União, aos Estados, ao Distrito Federal e aos Municípios' a cobrança de impostos, de acordo com seu Artigo 9º Inciso IV, letra c) sobre "o patrimônio, a renda ou serviços dos partidos políticos, inclusive suas fundações, das entidades sindicais dos trabalhadores, das instituições de educação e de assistência social, sem fins lucrativos, observados os requisitos fixados na Seção II deste Capítulo", assegura às instituições de educação superior privadas o benefício da renúncia fiscal, assinalando ao que mais tarde vai se concretizar, a opção pela privatização deste nível de ensino.

Sampaio (2011, p. 29) afirma que "liderada pela iniciativa privada, no início dos anos 1970, a expansão foi impulsionada pela pressão de diversos segmentos da sociedade brasileira, que se tornava cada vez mais urbana e industrializada" uma vez que "para um contingente cada vez maior da população, a formação superior passava a fazer parte de seus projetos de 
realização pessoal e de ascensão social". Sampaio (2011, p. 29) complementa destacando que "a iniciativa privada, atenta às demandas de novos e potenciais consumidores, respondeu de forma ágil” e, apoiando-se na legislação disponível (LDB, 1061, reforma Universitária, 1968) “a expansão logrou rapidamente estabelecer uma relação de complementaridade entre o setor público e o privado" (SAMPAIO, 2011, p. 29).

A década de 80 foi marcada por uma crise econômica decorrente do aumento das taxas de juros internacionais ocasionado pelas crises do petróleo em 1973 e 1979, que reverteram o fluxo de divisas para os países centrais, e o ajuste promovido pela política econômica do período provocou aumento da inflação, estagnação econômica e a queda dos salários reais (CARVALHO, 2007, p. 89).

Para Durham (2003, p. 20-1) "A década de 80 foi um período de crise e de transição" destacando que "Politicamente, é caracterizada pelo longo e gradual processo de redemocratização que se iniciou com um declínio da repressão política, prosseguiu com a eleição de um presidente civil pelo Congresso em 1985 e terminou com uma nova Constituição em 1988". Mas, pontua que "economicamente, é uma década de crise econômica e inflação crescente. No ensino superior é uma época de estagnação".

Schwartzman (1996, p. 1) ao discutir as políticas para a educação superior na década de 1990 lembra que "para o setor privado o Crédito Educativo consistia na principal forma de ajuda, ao assegurar o pagamento das anuidades para um expressivo número de alunos".

Em meados dos anos 90, no Governo Fernando Henrique Cardoso, houve a adoção de uma política econômica baseada no ajuste fiscal e na implantação da reforma do Estado para reverter à situação de crise econômica enfrentada pelo Estado brasileiro desde os anos 80. A crítica ao Estado Intervencionista e a busca da minimização de sua atuação no que se refere às políticas sociais foram prescritas como solução para a retomada do crescimento econômico por meio de sua reforma.

Para Dourado (2011, p. 56), naquela década se dá a consolidação da privatização da educação superior, concretizada a partir da "diversificação e diferenciação institucional nesse nível de ensino, num cenário marcado pela reforma do Estado - ancorada na perspectiva de minimização do papel do Estado diante das políticas públicas".

A reforma que procurava superar os problemas de desemprego, hiperinflação e redução do crescimento econômico ocorreu a partir de 1995, aliada aos objetivos de modernização e racionalização. Luiz Carlos Bresser Pereira, então Ministro da Administração Federal e Reforma do Estado (MARE), no Governo Fernando Henrique, propôs uma reforma estatal e 
Programa Universidade para Todos (PROUNI): efeitos financeiros em uma instituição de educação superior privada

apresentou um Plano Diretor, sugerindo mudanças nas formas de organização e gestão do Estado brasileiro.

Estas mudanças buscavam alterar o papel do Estado que deveria deixar de ser o responsável direto pelo desenvolvimento econômico e social por meio da produção de bens e serviços e deveria fortalecer seu papel de regulador desse desenvolvimento. Para tanto, faziase necessária a transferência, para o setor privado, das atividades que pudessem ser controladas pelo mercado. A privatização e a constituição do setor público, não estatal, seriam os grandes instrumentos de execução desses serviços.

Deste modo, a educação superior no governo de Fernando Henrique foi reduzida à condição de mercadoria e diagnosticada como espaço a ser assumido pelo mercado, capaz de dotar-lhe de competitividade, gerindo-a de modo mais eficiente que o Estado (SGUISSARDI, 2006).

A adoção desse modelo político econômico nos anos 90, de modo geral, contribuiu para a diversificação institucional da educação superior expressa por meio dos dados do Censo do Ensino Superior, os quais mostram que no Brasil havia, em 1996, um total de 922 instituições de Educação Superior. Em 2005, estas instituições somavam 2.169, sendo 176 Universidades, 114 Centros Universitários, 117 Faculdades Integradas, 1.574 Faculdades/Escolas/Institutos e 184 Centros Federais de Educação Tecnológica e Faculdades de Tecnologia.

Essa ampliação da oferta de vagas pelas IES privadas desencadeou o problema das vagas ociosas no setor que se associa a impossibilidade da população de pagar as mensalidades cobradas por essas instituições. Santos (2016, p. 56) entende que o setor privado foi apoiado por uma série de legislações, propiciando o crescimento deste segmento, e cita como exemplo:

a Lei n. 10.260/2001, que cria o Fundo de financiamento Estudantil (FIES); o Decreto n. 4.914, de 11/12/2003, que concede autonomia aos centros universitários; o Decreto n. 5.622, de 19/12/2005, que regulamenta a educação a distância (EaD); e a Medida Provisória n. 213 de 2004, transformada em Lei n. 11.096/2005 que instituiu o Programa Universidade Para Todos - ProUni.

Em 2002, as expectativas em torno da eleição de Luiz Inácio Lula da Silva foram significativas, em particular, dos segmentos populares que vislumbravam em sua eleição a inauguração de uma nova fase no cenário político nacional, que apresentasse alterações no quadro da política econômica do governo antecessor.

De modo geral, as medidas de política econômica adotadas por Luís Inácio Lula da Silva no início de seu primeiro mandato indicavam uma continuidade do que vinha sendo 
implementado pelo governo de Fernando Henrique uma política que priorizava o ajuste fiscal e o pagamento da dívida brasileira. No primeiro mandato do Governo Lula (2003-2006), a educação superior foi debatida a partir da criação do Grupo de Trabalho Interministerial (GTI), que, dentre seus objetivos, tinha a intenção de regulamentar a relação entre o Estado e as Instituições de Educação Superior, tanto públicas quanto privadas.

Dentre as medidas propostas pelo GTI pode-se destacar, em 2004, a criação do Programa Universidade para Todos (Prouni), por meio da Medida Provisória no 213/2004 (BRASIL, 2004), e implementado no Governo Lula, em 2005, pela Lei Federal no 11.096/2005 (BRASIL, 2005), tendo como finalidade a concessão de bolsas de estudos, integrais e parciais, a estudantes brasileiros sem diploma de nível superior, matriculados em cursos de graduação de instituições privadas.

O PROUNI vincula-se ao projeto de democratização do acesso à educação superior no Governo de Luís Inácio Lula da Silva. O programa contempla alunos carentes, mas exige que se obedeçam alguns critérios, como baixa renda familiar, bem como destina um percentual de bolsas para alunos autodeclarados negros, indígenas e portadores de deficiência, e beneficia a formação de professores de ensino básico da rede pública.

Embora a posição dos alunos e das IES privadas seja favorável à implantação do PROUNI, conforme abordam Oliveira (2012) e Foreque (2013), este também recebe críticas, principalmente de pesquisadores ligados ao setor público, ao indicarem que o programa incentiva a oferta privada de educação e favorece o crescimento do setor privado a partir das isenções fiscais.

Diante deste quadro inicial, propõe-se como objetivo deste artigo verificar quais os efeitos do PROUNI numa IES Privada, após a adesão ao programa. O propósito é o de identificar se a isenção fiscal obtida após adesão ao Prouni a instituição supera os investimentos em bolsas de estudos do programa.

A abordagem metodológica proposta para este trabalho consiste em uma pesquisa documental e os dados que a subsidiaram foram coletados com autorização do seu mantenedor em uma IES Privada, com fins lucrativos, localizada no município de Cotia, no Estado de São Paulo que aderiu ao Programa Universidade para Todos em 2008.

Os principais documentos utilizados foram os Balanços Patrimoniais dessa IES e os termos de adesão que são os documentos gerados a partir das informações prestadas pelas IES que aderem ao PROUNI pelo Sistema Informatizado do Programa Universidade para Todos (SISPROUNI) no site do Ministério da Educação. 
Programa Universidade para Todos (PROUNI): efeitos financeiros em uma instituição de educação superior privada

Identificou-se relevante e significativa a discussão acerca do financiamento da educação superior envolvendo autores e pesquisadores, tais como Amaral (2003), Sguissardi (2000, 2001, 2008), Carvalho (2005, 2006a, 2006b, 2007), Catani (2006), Dourado (2002, 2011), Mancebo (2004), Santos (2016) e Chaves (2015). Levantamento junto ao Banco de Teses da Coordenação de Aperfeiçoamento de Pessoal de Nível Superior (CAPES) ainda apurou 32 pesquisas de mestrado e 15 de doutorado que tratam da questão do financiamento da educação superior (PARDO; HAAS, 2014). Apesar da busca, não foram localizadas pesquisas que tratam dos efeitos financeiros institucionais a partir da adesão ao PROUNI ou que contemplassem os dados contábeis de instituições de educação superior. Assim, é importante destacar que foi possível desenvolver esta pesquisa a partir da autorização do mantenedor que disponibilizou para o estudo, os balanços patrimoniais e outros documentos institucionais.

Para esclarecimento sobre a adesão da IES ao PROUNI e também com o propósito de conhecer a opinião do administrador da instituição em relação ao programa, foi realizada uma entrevista semiestruturada com o mantenedor.

\section{Programa Universidade Para Todos (PROUNI)}

Em 10 de setembro de 2004, foi criado o Programa Universidade Para Todos (PROUNI) por meio da Medida Provisória ${ }^{\circ}$. 213, consolidado no Governo Lula, em 13 de janeiro de 2005, pela Lei Federal nº 11.096 (BRASIL, 2004, 2005). O programa tem como objetivo favorecer o acesso de estudantes de baixa renda à educação superior privada, mediante concessão de bolsas de estudos por essas IES, que passam a ter, em contrapartida, a isenção de impostos, como Imposto de Renda de Pessoa Jurídica (IRPJ), a Contribuição Social sobre o Lucro Líquido (CSLL), o Programa de Integração Social (PIS) e a Contribuição para o Financiamento da Seguridade Social (COFINS).

O IRPJ, uma das isenções asseguradas para as IES que aderem ao PROUNI, está previsto no artigo 153 da Constituição Federal de 1988. No Código Tributário Nacional, o imposto de renda é tratado nos artigos 43,44 e 45 e no âmbito da legislação ordinária existem inúmeras leis, decretos-lei e medidas provisórias que disciplinam este imposto. Tais legislações estão consolidadas no Regulamento do Imposto de Renda.

As pessoas jurídicas têm seus lucros tributados pelo IRPJ à alíquota de 15\%, que pode ser acrescida de um adicional de $10 \%$ sobre a parcela do lucro mensal que exceder a vinte mil reais, conforme disposto no artigo $3^{\circ}$, da Lei Federal $n^{\circ}$. 9.249/1995. As instituições tributadas 
pelo lucro real poderão apurar o imposto de renda tomando-se como base de cálculo o lucro anual (BRASIL, 1995).

As IES que fizeram adesão ao PROUNI estão obrigadas a adotar o regime de tributação do Lucro Real ${ }^{1}$.

A Contribuição Social sobre o Lucro Líquido (CSLL) é uma fonte de recursos prevista no artigo 195, Inciso I, da Constituição Federal, estabelecido para atender ao programa de seguridade social. As instituições sem fins lucrativos e entidades beneficentes são isentas da cobrança do imposto. A base de cálculo da contribuição para IES com fins lucrativos é o valor obtido do resultado do exercício - lucro -, antes da provisão para o imposto de renda. A alíquota é de 9\% para estas instituições.

A isenção também abrange a contribuição para o Programa de Integração Social (PIS) que foi instituída pela Lei Complementar $n .^{\circ} 7$, de 7 de setembro de 1970, e recepcionada pelo art. 239 da Constituição Federal em vigor (BRASIL, 1970, 1988).

O PIS é destinado ao custeio do seguro-desemprego e ao abono de um salário mínimo anual aos empregados que recebem até dois salários mínimos, desde que sejam participantes do programa. Trata-se de uma contribuição social calculada sobre a receita bruta. Para as instituições com fins lucrativos. A alíquota do PIS é de 1,65\%.

A contribuição para o Financiamento da Seguridade Social (COFINS) foi instituída pela Lei Complementar n. ${ }^{\circ}$ 70, de 30 de dezembro de 1991 (BRASIL, 1991). Seus recursos são destinados para as áreas da saúde, previdência e assistência social. Para IES com fins lucrativos, sua alíquota é de 7,6\% e incide sobre a receita mensal.

Em conformidade com a Lei Federal $n^{\circ} .11 .096 / 2005$, as IES que aderem ao programa ficam isentas dos impostos acima mencionados e devem conceder bolsas integrais e parciais, de $50 \%$ e $25 \%$, para estudantes de cursos de graduação e sequenciais de formação.

A bolsa de estudo integral será concedida a brasileiros que não possuem diploma de curso superior, cuja renda familiar mensal per capita não exceda o valor de até um salário mínimo e meio. As bolsas parciais de $50 \%$ e $25 \%$ são destinadas a estudantes cuja renda familiar mensal per capita não ultrapasse três salários-mínimos. Conforme Art. $2^{\circ}$, as bolsas destinam-se a:

Art $2^{\circ}-[\ldots]$

I- estudante que tenha cursado o ensino médio completo em escola da rede pública ou em instituições privadas na condição de bolsista integral;

II- a estudante portador de deficiência, nos termos da lei;

1 O lucro real é o lucro contábil líquido apurado na escrituração contábil, ajustado por adições e exclusões ou compensações autorizadas pela legislação fiscal, conforme dispõe o artigo 247 do Decreto 3.000/1996. 
Programa Universidade para Todos (PROUNI): efeitos financeiros em uma instituição de educação superior privada

III- o professor da rede pública de ensino, para os cursos de licenciatura, normal superior e pedagogia, destinados à formação do magistério da educação básica, independentemente da renda (BRASIL, 2005).

O PROUNI prevê, ainda, vagas a cidadãos autodeclarados indígenas, pardos ou pretos, conforme o artigo $7^{\circ}, \S 1^{\circ}$, da Lei Federal $n^{\circ} .11 .096 / 2005$, instituidora do PROUNI:

Art. $7^{\circ}$. - As obrigações a serem cumpridas pela instituição de ensino superior serão previstas no termo de adesão ao PROUNI, no qual deverão constar as seguintes cláusulas necessárias:

I- $\quad$ proporção de bolsas de estudo oferecidas por curso, turno e unidade, respeitados os parâmetros estabelecidos no art. $5^{\circ}$ desta Lei;

II- percentual de bolsas de estudos destinado à implementação de políticas afirmativas de acesso ao ensino superior de portadores de deficiência ou de autodeclarados indígenas e negros (BRASIL, 2005).

Podem se candidatar ao processo seletivo PROUNI apenas os estudantes que tenham realizado o Exame Nacional do Ensino Médio (ENEM), cujo resultado seja, no mínimo, 450 pontos na média das cinco provas, o que equivale a $40 \%$ de acertos em Redação, Linguagens, Códigos e suas Tecnologias, Matemática e suas Tecnologias, Ciências Humanas e suas Tecnologias e Ciências da Natureza e suas Tecnologias. Os candidatos devem ainda ter obtido nota superior a zero na Redação.

A adesão ao programa para as IES privadas com fins lucrativos é voluntária e o Termo de Adesão terá prazo de vigência de dez anos, contado da data de sua assinatura, renovável por iguais períodos, observado o disposto em lei.

As IES privadas com fins lucrativos ou sem fins lucrativos não beneficentes devem oferecer, no mínimo, uma bolsa integral a cada 10,7 estudantes regularmente pagantes e devidamente matriculados ao final do correspondente período letivo anterior. Conforme Art. $5^{\circ}$. da norma em questão, as instituições podem optar por oferecer uma bolsa integral a cada 22 estudantes regularmente pagantes e devidamente matriculados em cursos em efetivo funcionamento, desde que oferte bolsas parciais de $50 \%$ e $25 \%$ na proporção necessária para que se atinja o equivalente a $8,5 \%$ da receita anual.

\footnotetext{
Art. $5^{\circ}-[\ldots]$

$\S 4^{\circ}[\ldots]$ na proporção necessária para que a soma dos benefícios concedidos na forma desta Lei atinja o equivalente a $8,5 \%$ (oito inteiros e cinco décimos por cento) da receita anual dos períodos letivos que já têm bolsistas do PROUNI, efetivamente recebida nos termos da Lei no 9.870, de 23 de novembro de 1999, em cursos de graduação ou sequencial de formação específica (BRASIL, 2005).
}

No contexto de renúncia fiscal, a instituição do PROUNI destaca-se no estudo realizado por Carvalho (2006a), cabendo demonstrar na Tabela 1 os benefícios fiscais obtidos pelas instituições de educação superior privadas que aderissem ao programa comparando os dados das entidades com fins lucrativos, daquelas sem fins lucrativos confessionais, das comunitárias e das filantrópicas, antes e depois de sua adesão ao programa. 
A renúncia fiscal no PROUNI na visão de Carvalho (2006a) tornou-se um mecanismo viável para amenizar o problema das IES privadas com relação ao preenchimento de vagas ociosas. Os dados da Tabela 1 indicam que as instituições mais beneficiadas são aquelas com fins lucrativos que ficam isentas, a partir da adesão ao PROUNI, do recolhimento dos impostos federais: IRPJ, CSLL, COFINS e PIS.

Tabela 1 - Alíquotas e base de cálculo dos tributos federais por categoria de IES

\begin{tabular}{|c|c|c|c|c|c|c|}
\hline \multirow{3}{*}{ Impostos } & \multirow{2}{*}{\multicolumn{2}{|c|}{ Com fins lucrativos }} & \multicolumn{4}{|c|}{ Sem fins lucrativos } \\
\hline & & & \multicolumn{2}{|c|}{ Confessional/Comunitária } & \multicolumn{2}{|c|}{ Filantrópica } \\
\hline & Atual & PROUNI & Atual & PROUNI & Atual & PROUNI \\
\hline IRPJ & $15 \%$ lucro & - & & - & - & - \\
\hline CSLL & $9 \%$ lucro & - & & - & - & - \\
\hline COFINS & $7,6 \%$ receita & - & $3 \%$ receita & - & - & - \\
\hline PIS & $1,65 \%$ receita & - & $1 \%$ folha & - & $1 \%$ folha & - \\
\hline $\begin{array}{l}\text { INSS } \\
\text { (patronal) }\end{array}$ & $20 \%$ folha & $20 \%$ folha & $20 \%$ folha & $20 \%$ folha & - & - \\
\hline
\end{tabular}

Fonte: CARVALHO (2006a). O PROUNI no Governo Lula e o jogo político em torno do acesso ao ensino superior.

Sguissardi (2006) argumenta que o programa fortalece as IES Privadas configurandose transferência de recursos públicos para o setor privado na forma de isenção fiscal, sendo mais beneficiadas com o programa as instituições privadas com fins lucrativos. Destaca-se ainda o fato de que essas instituições foram as que mais exerceram pressão quando da tramitação do Projeto de Lei no Congresso para que fossem atendidas suas exigências.

O programa, pretextando a publicização do privado, na forma como foi aprovado e está sendo implementado, fortalece as instituições privadas comerciais de ensino. Pode-se entendê-la como forma de aplicação lato sensu do espírito das PPPs no campo do ensino superior. Em troca da isenção de um conjunto de impostos pelas IES privadas - o programa é muito mais interessante para as instituições com fins lucrativos - aprovou-se a possibilidade de troca de cerca de $10 \%$ das vagas ou $8,5 \%$ da receita bruta, na forma de bolsas para alunos egressos de escolas públicas (SGUISSARDI, 2006, p. 1043).

Corroborando a afirmação de Sguissardi podem-se apontar os dados do MEC/PROUNI de que as instituições mais beneficiadas foram as com fins lucrativos, pois, de acordo com informações do site do Ministério da Educação/PROUNI, essas instituições contabilizam 56\% de bolsistas. Seguem as entidades beneficentes de assistência social, com 27\% de bolsistas; e as instituições sem fins lucrativos não beneficentes, com $17 \%$ de bolsistas (BRASIL, 2012). 
Programa Universidade para Todos (PROUNI): efeitos financeiros em uma instituição de educação superior privada

Mancebo (2004) informa que o aproveitamento de parte das vagas ociosas das instituições de educação superior privadas para o PROUNI, com bolsas de estudo, possibilitará a elevação do volume de matrícula viabilizando o ingresso de 300 mil novos alunos.

Mancebo (2004, p. 853) acrescenta: “Com relação a esse Programa, deve-se insistir no seu aspecto privatizante, também, porque ele delega responsabilidades públicas para entidades privadas e, mesmo que os alunos não paguem mensalidades, contribui para o aumento da oferta privada nesse campo".

Corroboram a afirmação de Mancebo, os dados estatísticos do Censo 2010 do MEC/INEP, quando evidenciam que a expansão das instituições privadas de educação superior nos últimos anos resultou no aumento das matrículas que nos cursos de graduação atingiram $110,1 \%$, na última década. De um total de 2.377 instituições de educação superior no país, 2.099 são privadas, o que permite contabilizar 4.736.001 de alunos matriculados, enquanto que 278 são instituições públicas e totalizam 1.643.029 de matrículas.

A crítica é de que o PROUNI promove uma política de acesso à educação superior pela transferência de recursos públicos para entidades privadas, pelo não recolhimento de tributos federais, aumentando a oferta privada da educação superior em detrimento da criação de novas vagas nas universidades públicas (CARVALHO, 2006a, 2006b; SGUISSARDI, 2006; MANCEBO, 2004; CHAVES, 2015).

\section{Programa Universidade Para Todos (PROUNI) em uma instituição de educação supe- rior privada: Resultados da adesão}

De acordo com o Plano de Desenvolvimento Institucional (PDI), a faculdade, estudada nessa investigação, iniciou suas atividades no primeiro semestre de 2007, com a implantação dos cursos de Direito no período noturno e Fisioterapia nos períodos diurno e noturno. No segundo semestre de 2007, seguiu-se a criação dos cursos de Administração, período noturno, e Biomedicina nos períodos diurno e noturno. Os cursos de Gastronomia e de Pedagogia passaram a ser oferecidos a partir do primeiro semestre de 2008, ambos com turmas no período noturno. O curso de Marketing foi autorizado e iniciou a primeira turma no primeiro semestre de 2009, com aulas ministradas no período noturno.

É importante destacar que a instituição aderiu aos programas de financiamento estudantil, FIES e PROUNI, logo após aprovação de seu credenciamento junto ao MEC, em 2007. No que diz respeito ao PROUNI, os primeiros beneficiários ingressaram na Faculdade no primeiro semestre de 2008. Um dos principais desafios para esta instituição, que atua no mer- 
cado de educação superior, há apenas seis anos, é aumentar a sua demanda nos cursos de graduação. Neste sentido, o PROUNI favorece esta IES, pois, a partir de sua adesão ao programa, a instituição tem seu nome divulgado no site do MEC/PROUNI.

Almeida (2017, p. 109) argumenta que o PROUNI serviu para aliviar os custos operacionais e as despesas fixas da IES privadas. " A troca de bolsas de estudo do Prouni por isenções fiscais ajudou as instituições com fins lucrativos a sobreviverem em um quadro de grave crise iniciado nos 1990 e 2000".

Um dos principais documentos utilizados para esse estudo foi o termo de adesão ao programa que é gerado pelo sistema Sisprouni após a adesão da IES ao programa e é composto por dez itens. O primeiro refere-se aos dados cadastrais da mantenedora no qual se destacam: razão social: CNPJ; código da mantenedora no INEP; categoria na qual a instituição pesquisada se enquadra em sociedade simples e com fins lucrativos; nome completo do responsável legal da mantenedora; CPF; cargo; telefone; e e-mail.

Sem desconsiderar a relevância de todos os 10 itens, é importante destacar no Termo o item 7, pois nesse, a IES apresenta o quadro de bolsas do PROUNI. No que se refere às bolsas oferecidas de acordo com a Lei Federal $\mathrm{n}^{\mathrm{o}}$. 11.096/2005. A IES em estudo optou por ofertar uma bolsa para cada 22 alunos pagantes e bolsas complementares de $50 \%$, até que se atinja o percentual equivalente de $8,5 \%$ de sua receita.

As bolsas de estudos integrais no Projeto de Lei deveriam ser destinadas a alunos, cuja renda familiar per capita não fosse superior a um salário mínimo. Entretanto, na Medida Provisória, essa oferta abrange alunos cuja renda seja de um salário mínimo e meio e ainda há a possibilidade de bolsas parciais de $50 \%$ e $25 \%$, para bolsistas com renda de até três salários mínimos.

A alteração acima mencionada, na quantidade de bolsas oferecidas pelas IES Privadas representou uma vitória para o setor privado que poderia, por conta da alteração na Lei 11.096/2005, no sentido de aumentar a quantidade de alunos beneficiados pelo programa a partir da oferta das bolsas parciais de $50 \%$ e $25 \%$.

A Tabela 2 apresenta a quantidade de bolsas parciais ofertadas pela instituição com sua adesão ao PROUNI. Considerando a oferta dessas a instituição deve de acordo com a Lei 11.096 oferecer bolsas parciais até $8,5 \%$ de sua receita auferida com base nos números do ano anterior.

Há um entendimento por parte do mantenedor de que a IES deve ofertar, de acordo com a Lei Federal no $n^{\circ}$ 11.096/2005, um limite máximo de até 8,5\% da receita auferida em bolsas parciais. Entretanto, segundo ele se não há demanda para preencher todas as bolsas par- 
Programa Universidade para Todos (PROUNI): efeitos financeiros em uma instituição de educação superior privada

ciais que são oferecidas semestralmente, estas não precisam ser totalmente ocupadas, somente as bolsas integrais são totalmente preenchidas. Afirma, ainda, que houve queda da demanda por bolsas parciais em alguns cursos oferecidos pela instituição.

Tabela 2 - Bolsas parciais (50\%) obrigatórias (2008-2011)

\begin{tabular}{lcccccccc}
\hline \multicolumn{1}{c}{ Curso } & $\begin{array}{c}\text { 10 Sem } \\
\text { 2008 }\end{array}$ & $\begin{array}{c}\mathbf{2 0} \text { Sem } \\
\mathbf{2 0 0 8}\end{array}$ & $\begin{array}{c}\text { 10 Sem } \\
\mathbf{2 0 0 9}\end{array}$ & $\begin{array}{c}\text { 20 Sem } \\
\mathbf{2 0 0 9}\end{array}$ & $\begin{array}{c}\text { 10 Sem } \\
\mathbf{2 0 1 0}\end{array}$ & $\begin{array}{c}\text { 20 Sem } \\
\mathbf{2 0 1 0}\end{array}$ & $\begin{array}{c}\text { 10 Sem } \\
\mathbf{2 0 1 1}\end{array}$ & $\begin{array}{c}\text { 20 Sem } \\
\mathbf{2 0 1 1}\end{array}$ \\
\hline Pedagogia & 30 & 2 & 7 & 4 & 4 & 0 & 0 & 2 \\
Administração & 30 & 3 & 0 & 4 & 0 & 3 & 2 & 1 \\
Direito & 26 & 2 & 11 & 4 & 6 & 3 & 8 & 3 \\
Biomedicina & 26 & 2 & 9 & 3 & 0 & 3 & 4 & 3 \\
Enfermagem & 0 & 0 & 0 & 0 & 4 & 4 & 3 & 3 \\
Fisioterapia & 26 & 3 & 4 & 3 & 0 & 4 & 3 & 1 \\
Gastronomia & 13 & 2 & 7 & 4 & 4 & 4 & 8 & 0 \\
Marketing & 0 & 3 & 8 & 4 & 4 & 3 & 1 & 2 \\
Ed Física & 0 & 0 & 0 & 4 & 4 & 4 & 3 & 0 \\
Eng. Civil & 0 & 0 & 0 & 0 & 4 & 4 & 9 & 4 \\
\hline Total & 151 & 17 & 46 & 30 & 30 & 32 & 41 & 19 \\
\hline
\end{tabular}

Fonte: Termo de Adesão / Elaboração própria.

Considerando que este artigo tem como propósito avaliar se a adesão da IES ao PROUNI resultou em um benefício fiscal que possa ter superado os investimentos em bolsas de estudos ofertados pela instituição, os valores da receita e do lucro foram essenciais para este estudo.

Assim, foi necessário determinar se a isenção fiscal alcançada pela instituição de educação superior privada supera os investimentos em bolsas de estudos oferecidas pela mesma após sua adesão ao PROUNI. Para esta avaliação foi preciso calcular os impostos relacionados ao programa que a instituição deixa de recolher para a devida comparação com os valores correspondentes ao investimento em bolsas de estudo feitas pela IES.

Este cálculo foi elaborado com base nos resultados globais consolidados, que consistem nos valores da receita e do lucro anual divulgados pela instituição em seus balanços patrimoniais, que servem de base para verificação da carga tributária da instituição.

Os valores despendidos ${ }^{2}$ em bolsas de estudos integrais e parciais de $50 \%$ do PROUNI foram calculados a partir do valor da mensalidade média, aplicada anualmente, em todos os cursos da IES. Estes valores foram coletados dos termos de adesão.

2 Ao oferecer bolsas de estudos do PROUNI, a Instituição deixou de receber as matrículas e mensalidades correspondentes, para se beneficiar da isenção fiscal. 
Como já apresentado neste estudo a IES pesquisada é uma instituição com fins lucrativos, portanto, a mesma fica isenta do pagamento de alguns impostos federais, após sua adesão ao PROUNI.

A Tabela 3 apresenta o cálculo anual da isenção fiscal alcançada pela Instituição no período 2008-2010.

Tabela 3 - Demonstrativo da isenção fiscal em função da adesão da IES ao PROUNI (2008-2010)

\begin{tabular}{llllrrrr}
\hline \multicolumn{1}{c}{ Período } & Receita & Lucro & PIS & COFINS & IRPJ & CSLL & \multicolumn{1}{c}{$\begin{array}{c}\text { Isenção } \\
\text { Fiscal }\end{array}$} \\
\hline 2008 & 1.643 .774 & & 27.122 & 124.926 & 0,00 & 0,00 & 152.048 \\
2009 & 4.167 .863 & \multirow{2}{*}{110.562} & 68.770 & 316.757 & 16.584 & 9.950 & 412.061 \\
2010 & 7.029 .348 & & 115.984 & 534.230 & 0,00 & 0,00 & 650.214 \\
\hline Total & 12.999 .121 & 110.562 & 214.485 & 987.931 & 16.584 & 9.950 & 1.214 .323 \\
\hline
\end{tabular}

Fonte: Balanços patrimoniais / Elaboração própria.

Notas: a) Valores expressos em reais; e

b) A instituição não apurou lucro nos anos de 2008 e 2010.

Os dados da Tabela 3 mostram a isenção fiscal alcançada pela IES desde 2008 até o final do período analisado, em 2010. O valor total da isenção nesse período foi de $\mathrm{R} \$$ 1.214.323.

A partir do estudo dos balanços patrimoniais, verificou-se que a isenção fiscal em relação aos impostos COFINS e PIS, cuja base de cálculo é a receita anual, ocorreu em todo período analisado.

Entretanto, como a IES não apresentou lucro nos anos de 2008 e 2010, não fez o recolhimento do Imposto de Renda e da Contribuição sobre o Lucro Líquido nesses anos. Embora sem apresentar lucro em todo o período estudado e sem realizar o recolhimento dos impostos incidente sobre o lucro nos anos de 2008 e 2010, a instituição beneficiou-se da isenção fiscal deixando de recolher aos cofres públicos o valor total de $\mathrm{R} \$ 1.214 .323,00$. Este ganho de mais de um milhão de reais refere-se aos impostos que deveriam incidir sobre a sua receita de 2008 a 2010, bem como sobre o lucro no ano de 2009 que a IES deixou de pagar.

Pode-se considerar que o valor desta isenção é relevante para esta instituição que pode utilizar o valor correspondente aos impostos não pagos para ampliar suas instalações físicas, bem como o benefício fiscal ainda contribui para a sua atuação competitiva no mercado.

A receita que compôs a base de cálculo dos tributos foi a efetivamente recebida, pois foram descartadas para o cálculo, as mensalidades em atraso, consideradas inadimplências. 
Programa Universidade para Todos (PROUNI): efeitos financeiros em uma instituição de educação superior privada

A Tabela 4 apresenta dados relativos ao investimento ${ }^{3}$ da IES em bolsas de estudos relacionados ao PROUNI, as bolsas são integrais de $100 \%$ e parciais de $50 \%$ e estes valores serão utilizados para verificar se o ganho fiscal supera os valores das bolsas PROUNI ofertadas pela instituição.

Os valores das bolsas relacionadas ao programa foram calculados ${ }^{4}$ considerando o valor da mensalidade média anual aplicada pela instituição em todos os cursos ofertados no período 2008-2010.

Tabela 4 - Investimentos realizados pela IES em bolsas de estudos (2008-2010)

\begin{tabular}{lcccc}
\hline Período & $\begin{array}{c}\text { Valor da mensali- } \\
\text { dade média }\left(^{*}\right)\end{array}$ & $\begin{array}{c}\text { Quantidade de bol- } \\
\text { sas integrais oferta- } \\
\text { das }\end{array}$ & $\begin{array}{c}\text { Quantidade de bolsas } \\
\text { parciais (50\%) oferta- } \\
\text { das }\end{array}$ & $\begin{array}{c}\text { Valor total investido } \\
\text { em bolsas }\left(^{*}\right)\end{array}$ \\
\hline 2008 & 501,91 & 29 & 753 & $203.524,51$ \\
2009 & 615,43 & 36 & 76 & $45.541,82$ \\
2010 & 644,77 & 27 & 62 & $37.396,66$ \\
\hline Total & & 92 & 891 & $286.462,99$ \\
\hline
\end{tabular}

Fonte: Termo de Adesão / Elaboração própria.

Notas: (*) Valores expressos em reais.

A tabela 4 demonstra o investimento feito pela IES em bolsas de estudos do PROUNI, (2008-2010) os dados mostram que a instituição ofereceu o total de 92 bolsas integrais e 891 bolsas parciais em todo período estudado.

O valor total investido em bolsas de estudos do PROUNI pela instituição foi de $\mathrm{R} \$ 286.462,99$, valor este que a IES deixou de receber com pagamento de mensalidades dos alunos beneficiados do programa no período 2008-2010.

Os dados apresentados na tabela 3 e 4 mostram que, mesmo sem obter lucro em 2008 e 2010, a IES beneficiou-se da isenção fiscal deixando de recolher aos cofres públicos o valor de R\$ 1.214.323. Em contrapartida, a IES investiu em bolsas de estudos relacionadas ao PROUNI o valor de R\$ 286.462,99, representando um ganho de R\$ 927.860,00.

Contudo, a economia fiscal alcançada a partir da isenção dos impostos relacionados ao PROUNI, apresentados na tabela 4, supera em $424 \%$ os investimentos em bolsas de estudos ofertadas pela Instituição no mesmo período.

\footnotetext{
Investimento em bolsas de estudo significa, neste trabalho, o valor de matrículas e mensalidades que correspondem às bolsas do PROUNI que a IES deixou de receber. Estes valores foram coletados nos termos de adesão.

4 Média Aritmética Simples - Corresponde à soma do valor total das mensalidades de todos os cursos da instituição a cada ano no período de 2008 a 2010 dividido pela quantidade de cursos oferecidos no mesmo período.
} 
Como indica Carvalho (2006a), se, por um lado, a renúncia fiscal representou a redução nos custos das instituições, por outro lado, esse tipo de incentivo implicou na redução da arrecadação tributária, o que poderia ser considerado como uma forma de transferência indireta de recursos financeiros às instituições de ensino privado.

Neste sentido, a transferência de recursos públicos concretizou-se na IES, apesar de só ter apresentado lucro no ano de 2009. Conforme apresentado na Tabela 3, a instituição beneficiou-se da isenção fiscal sobre os impostos que incide sobre sua receita deixando de recolher, entre 2008 e 2010, um montante ${ }^{5}$ de $\mathrm{R} \$ 1.202 .416$, relativo somente ao PIS e ao COFINS.

No ano de 2009, a instituição auferiu lucro. Portanto, beneficiou-se ainda mais da isenção fiscal, deixando de recolher nesse ano os impostos federais que incidem sobre a receita e o Lucro, os valores da isenção fiscal alcançados em 2009 e que estão apresentados na Tabela 3 mostram que a IES deixou de recolher um montante de $\mathrm{R} \$ 412.061,00$ referente aos valores de PIS e Cofins naquele ano.

A Tabela 5 demonstra que a IES investiu, no ano de 2008, em bolsas de estudos integrais e parciais, o valor de $\mathrm{R} \$ 203.524,00$, obtendo isenção fiscal de $\mathrm{R} \$ 152.048,00$, com recuperação de $75 \%$ do valor investido em bolsas de estudos PROUNI, índice considerável, lembrando que em 2008 a IES apresentou uma receita de apenas 152.048,00 e não obteve lucro, pois iniciou suas atividades no segundo semestre do ano anterior.

Tabela 5 - Isenção fiscal $x$ investimentos em bolsas de estudos (2008-2010)

\begin{tabular}{lcccc}
\hline Período & Isenção fiscal & $\begin{array}{l}\text { Investimento em } \\
\text { bolsas (R\$) }\end{array}$ & $\begin{array}{l}\text { Valor recuperado } \\
\text { (R\$) }\end{array}$ & \% Recuperado \\
\hline 2008 & 152.048 & 203.524 & -51.476 & $75 \%$ \\
2009 & 412.061 & 45.541 & 366.520 & $905 \%$ \\
2010 & 650.214 & 37.396 & 612.818 & $1739 \%$ \\
\hline Total & 1.214 .323 & 286.461 & 927.862 & $424 \%$ \\
\hline
\end{tabular}

Fonte: Termo de Adesão e Balanços patrimoniais / Elaboração própria.

A IES apurou lucro, em 2009, de $\mathrm{R} \$ 110.562,00$ e sua receita, conforme Tabela 3, aumentou consideravelmente, atingindo $\mathrm{R} \$ 4.176 .863,00$, o que proporcionou uma recuperação de $905 \%$ do valor investido, representando um ganho de $\mathrm{R} \$ 366.520,00$, somente nesse ano. Este dado demonstrou que a IES se beneficiou do não pagamento dos impostos relacionados ao PROUNI e o montante relativo a essa isenção fiscal superou os investimentos em bolsas de estudo em quase mil por cento no período em questão.

\footnotetext{
${ }^{5}$ Tabela 3 - Valor total do (PIS) 214.485,00 + Valor total da (COFINS) 987.931,00 = 1.202.416,00.
} 
Programa Universidade para Todos (PROUNI): efeitos financeiros em uma instituição de educação superior privada

Considerando que em 2010 a instituição investiu $\mathrm{R} \$$ 37.396,00 em bolsas de estudos, este valor representou um ganho real, somente nesse ano, de $\mathrm{R} \$ 612.818,00$. Em termos percentuais, a Tabela 4 mostra que esse ganho equivale a $1.739 \%$ do valor efetivamente recuperado sobre os investimentos em bolsas de estudo.

Os valores mencionados, relativos ao benefício fiscal obtido pela IES, são representativos e atendem as necessidades dessa instituição.

$\mathrm{Na}$ entrevista realizada para complementar o estudo, foi perguntado ao mantenedor se ele acredita que a adesão ao PROUNI favoreceu ganhos financeiros ou se o programa contribuiu para a expansão financeira da IES, tendo ele afirmado que desde o início das atividades da IES, em agosto de 2007, a instituição tem recebido centenas de alunos do PROUNI, o que trouxe dois resultados importantes para a instituição, quais sejam, o primeiro foi o aumento da quantidade de alunos, e o segundo, a redução fiscal e tributária resultante da adesão. Afirma ele, na entrevista:

\begin{abstract}
Sim, contribuiu para uma estabilização financeira da instituição, porque quando a instituição é nova, como no caso desta, tem vantagem em poder amortizar impostos que pagaria e que, de outra forma, não viria para cá e em uma região destas com uma instituição em crescimento, uma instituição ainda pequena acaba por ser conveniente nesta fase inicial de instalação, agora, se você pergunta se do PROUNI vieram diretamente recursos financeiros é lógico que não, pois você sabe que nem é a lógica do programa.
\end{abstract}

A resposta do mantenedor a esta questão confirma os dados coletados, os quais demonstraram o benefício da isenção fiscal no período 2008-2010, que, segundo o próprio mantenedor, contribui para a estabilização financeira da instituição. Neste sentido, verifica-se que o benefício fiscal alcançado por esta instituição contribuiu para sua manutenção.

A se considerarem os valores mencionados, bem como a fala do mantenedor, apreende-se que a isenção fiscal foi o principal motivo que levou a instituição à adesão ao PROUNI.

Para Carvalho (2006a, 2006b), o PROUNI é uma transferência indireta de recursos públicos para o setor privado. Por sua vez, na instituição estudada esta transferência indireta de recursos públicos concretiza-se da seguinte forma: o valor resultante de $\mathrm{R} \$ 1.214 .323,00$, fruto do não pagamento dos impostos que deveriam incidir diretamente na receita e no lucro desta IES, não recolhidos por conta da isenção propiciada pelo PROUNI, resulta ao final do exercício contábil ${ }^{6}$ em aumento real da receita e do lucro dessa instituição, materializando a transferência indireta de recursos públicos para iniciativa privada.

6 Ano fiscal ou exercício contábil é o período de tempo escolhido para se fazer a demonstração de resultados de uma instituição. 
Estudo realizado por Chaves (2015, p. 437) identifica que "a renúncia de impostos para o PROUNI vem aumentando a cada ano e, em 2013, representava quase $12 \%$ do montante de renúncia tributária vinculada à educação". E, complementa que, apesar da promessa de inserção dos menos favorecidos na educação superior, o PROUNI "tornou-se mais um dos mecanismos de indução da expansão do setor privado".

Neste sentido, os dados do censo da educação superior 2012 mostram que o número de matrículas no setor privado aumentou consideravelmente. Este número em 2001 representava 2.091.529, em termos percentuais, 68\%. Em 2010, o total de matrículas passou para 4.736.001. Em 2012 o número de matriculas no setor privado atingiu 5.140.312 anunciando que $74 \%$ do total das matrículas estavam no setor privado. Estes dados do censo indicam que as políticas direcionadas para educação superior nos últimos anos favoreceu a expansão da oferta pela via privada, contribuindo para expansão do setor privado como um todo.

Oliveira (2007) argumenta que o programa traduz conquistas sociais, enfatizando sua dimensão pública, e, de outro lado, ganhos para o mercado, enfatizando sua dimensão privada.

No que se refere à dimensão do público no programa, esta se concretiza em aspectos como a transparência de procedimentos e critérios eletrônicos. Estes critérios são préestabelecidos e envolvem aspectos meritórios e de necessidade social, bem como destaca a quase totalidade de bolsistas terem origem na rede estatal e a duplicação de negros e pardos na educação superior.

Para Oliveira (2007), a dimensão privada do PROUNI materializa-se a partir dos benefícios que o programa proporciona para as IES privadas com fins lucrativos a partir da isenção fiscal promovendo a expansão do setor.

Para confirmar se os efeitos da isenção tributária contribuem para o crescimento e a expansão da instituição, perguntou-se ao mantenedor se ele acreditava que o benefício fiscal tivesse alavancado o crescimento da instituição.

Afirmou, ele:

Não é uma fonte de recursos. É uma forma de você não pagar determinados impostos, mas, deste ponto de vista, com certeza traduz-se no lucro líquido, que impacta no resultado final.

Ao afirmar que "o não pagamento de determinados impostos impacta diretamente no resultado final da instituição", observa-se o entendimento de que o não pagamento dos impostos relacionados ao programa converge positivamente para o lucro da instituição e, vale repetir, para o resultado final. 
Programa Universidade para Todos (PROUNI): efeitos financeiros em uma instituição de educação superior privada

Sguissardi (2006, p. 1043) argumenta que "o programa, pretextando a "publicização" do privado, na forma como foi aprovado e está sendo implementado, fortalece as instituições privadas comerciais de ensino", fortalecendo as IES Privadas e, considera que se configura transferência de recursos públicos para o setor privado na forma de isenção fiscal, sendo mais beneficiadas com o programa as instituições privadas com fins lucrativos.

Chaves $(2015$, p. 438) afirma que a renúncia fiscal do PROUNI combinada com os recursos do FIES "tem beneficiado as instituições do setor privado que se expandem a cada ano, tornando o Brasil, o segundo país mais privatizado da América Latina (só perdendo para o Chile)".

No que se refere à expansão financeira da instituição em relação a sua adesão ao PROUNI, estudo realizado por Carvalho (2006a) sobre a isenção fiscal das instituições privadas sugere que o não recolhimento da COFINS e do PIS permite uma expansão de receita bruta. Isto ocorre nesta instituição, posto que o crescimento das matrículas aumenta sua receita bruta, em contrapartida, a IES beneficia-se de sua adesão ao PROUNI e não paga os impostos que incide sobre a sua receita. No final do exercício esta receita apresenta um crescimento real.

Neste sentido, os resultados desta pesquisa mostraram que a receita da IES aumentou, consideravelmente, no período analisado e contribuiu para o aumento do ganho fiscal pelo não recolhimento da COFINS e do PIS, pois, conforme os dados da Tabela 3, em 2010, a receita da instituição foi de $\mathrm{R} \$ 7.029 .348,00$ e o benefício fiscal alcançado pelo não pagamento da COFINS e do PIS apresentados na Tabela 5, naquele ano, foi de $\mathrm{R} \$ 650.214,00$. Este valor foi auferido pela instituição e não foi repassado ao governo federal.

Assim, os valores mencionados na Tabela 3 mostram que, mesmo sem apresentar lucro nos anos de 2008 e 2010, a isenção da COFINS e do PIS incidentes somente sobre a receita da IES garantiu um ganho fiscal que em todo período estudado atingiu R\$ 1.202.486,007 contribuindo para a sua estabilidade financeira.

\section{Considerações Finais}

O Programa Universidade para Todos (PROUNI) foi implantado pelo Governo de Luís Inácio Lula da Silva como um programa destinado a favorecer o acesso à educação superior privada por estudantes de baixa renda, mediante concessão de bolsas de estudos pelas

Conforme Tabela 3 este valor refere-se ao valor total da (COFINS) R \$ 987.931,00 + total (PIS) 214.485,00 = 1.202.416,00. 
Instituições de Ensino Superior (IES) privadas, e, em contrapartida, essas ficam isentas do pagamento de tributos federais.

Contudo, para demonstrar o quanto uma instituição privada beneficia-se com a dispensa de pagamento de impostos relacionados ao PROUNI, calculou-se a isenção fiscal alcançada, especificamente, por uma IES privada com fins lucrativos no período 2008-2010. Constatou-se que a instituição deixou de recolher aos cofres públicos o montante de $\mathrm{R} \$ 1.214 .323,00$ referente aos impostos federais no período estudado. Este dado demonstrou que se a IES não tivesse aderido ao programa recolheria em impostos o valor mencionado, relativo ao período de 2008 a 2010.

Para verificar se o benefício fiscal é superior ao valor que a instituição investiu em bolsas de estudo do PROUNI, apresentou-se o valor do investimento total realizado pela IES em bolsas de estudos do programa.

O investimento referiu-se às matrículas e mensalidades que a IES deixou de receber por ter aderido ao programa em 2008, disponibilizando bolsas de estudos integrais e parciais. O valor total dessas bolsas representou para IES, entre 2008 e 2010, um investimento de R\$ 286.462,00. Este dado evidenciou que o não pagamento de impostos superou o investimento da IES em bolsas do PROUNI, e, portanto, representou um ganho ${ }^{8}$ de $\mathrm{R} \$ 927.862,00$, que, em termos percentuais ${ }^{9}$ representa $424 \%$ do valor efetivamente recuperado sobre as bolsas de estudos direcionadas ao programa.

Este dado demonstrou que a IES se beneficiou financeiramente da sua adesão ao programa deixando de pagar impostos federais enquanto que, em contrapartida, seu investimento em bolsas do PROUNI foi bem inferior em relação ao ganho fiscal. Este ganho pode ser considerado, como observado por outros pesquisadores, a exemplo de Carvalho e Lopreato, (2005), Mancebo (2004) e Sguissardi (2006), uma realocação das verbas públicas para o setor privado.

Para Carvalho (2006a, 2006b), o PROUNI é uma transferência indireta de recursos públicos para o setor privado. Por sua vez, na instituição estudada esta transferência indireta de recursos públicos concretiza-se da seguinte forma: o valor resultante de $\mathrm{R} \$ 1.214 .323,00$, fruto do não pagamento dos impostos que deveriam incidir diretamente na receita e no lucro desta IES, não recolhidos por conta da isenção propiciada pelo PROUNI, resulta ao final do 
Programa Universidade para Todos (PROUNI): efeitos financeiros em uma instituição de educação superior privada

exercício contábil em aumento real da receita e do lucro dessa instituição, materializando a transferência indireta de recursos públicos para iniciativa privada.

Verificou-se, na entrevista, que o mantenedor é favorável ao programa por considerálo uma das mais importantes medidas do governo federal, avaliando positivamente a adesão da IES ao PROUNI, destacando que os principais resultados positivos dessa adesão foram o ganho fiscal para a instituição e o aumento na quantidade de alunos.

Os resultados desta pesquisa demonstraram que o ganho fiscal alcançado por esta IES após sua adesão ao programa contribuiu financeiramente para sua estabilização. Pode-se, pois, inferir que o aumento da receita e do lucro pela desobrigação do recolhimento de impostos federais contribui para manutenção e uma possível expansão da instituição.

Os dados levantados neste estudo evidenciam, ainda, que o PROUNI se consolida na sua dimensão privada ao promover a transferência de recursos públicos para a iniciativa privada na forma de isenções tributárias e proporciona ganhos financeiros para este setor, contribuindo para sua expansão.

Finalizando, convém registrar que há a necessidade da realização de novas pesquisas, buscando aprofundamento e melhor avaliação dos efeitos financeiros nas Instituições Privadas de Educação Superior em função da adesão ao PROUNI, sendo considerada uma ação estratégica, inclusive, traçar estudos comparativos, valendo-se de dados e resultados de outras instituições. Cumpre sugerir, ainda, que os efeitos não sejam analisados somente em relação ao investimento em bolsas de estudos direcionadas ao programa, mas, também, com relação a outros custos de manutenção das instalações da instituição e com a folha de pagamento de funcionários.

\section{Referências}

ALMEIDA, Wilson Mesquita de. Prouni sob balanço: avanços e limites à luz de experiências estudantis na cidade de São Paulo: o negócio da educação a aventura das universidades privadas na terra do capitalismo sem risco. São Paulo: Olho D'agua, 2017.

AMARAL, Nelson Cardoso. Financiamento da educação superior: estado x mercado. São Paulo: Cortez; Piracicaba: UNIMEP, 2003.

BRASIL. Lei Complementar n. ${ }^{\circ}$, de 7 de setembro de 1970. Institui o Programa de Integração Social, e dá outras providências. 1970. Disponível em: <http://www.planalto.gov.br/ccivil_03/leis/LCP/Lcp07.htm>. Acesso em: 15 dez. 2011.

BRASIL. Constituição da República Federativa do Brasil de 1988. 1988. Disponível em: <http://www.planalto.gov.br/ccivil_03/constituicao/constituicao.htm>. Acesso em: 15 dez. 2011. 
BRASIL. Lei Complementar n. ${ }^{0}$ 70, de 30 de dezembro de 1991. Institui contribuição para financiamento da Seguridade Social, eleva a alíquota da contribuição social sobre o lucro das instituições financeiras e dá outras providências. 1991. Disponível em:

<http://www.planalto.gov.br/ccivil_03/leis/LCP/Lcp70.htm>. Acesso em: 16 dez. 2011.

BRASIL. Lei Federal n⿳0 9.249, de 26 de dezembro de 1995. Altera a legislação do imposto de renda das pessoas jurídicas, bem como da contribuição social sobre o lucro líquido, e dá outras providências. 1995. Disponível em:

<http://www.planalto.gov.br/ccivil_03/leis/L9249.htm>. Acesso em: 15 dez. 2011.

BRASIL. Medida Provisória no. 213, de 10 de setembro de 2004. Institui o Programa Universidade para Todos - PROUNI, regula a atuação de entidades beneficentes de assistência social no ensino superior, e dá outras providências. 2004. Disponível em:

<http://www.planalto.gov.br/ccivil_03/_ato2004-2006/2004/Mpv/213.htm>. Acesso em: 14 set. 2011.

BRASIL. Lei Federal no 11.096, de 13 de janeiro de 2005. Institui o Programa Universidade para Todos - PROUNI; altera a Lei no 10.891, de 9 de julho de 2004, e dá outras providências. 2005. Disponível em: <http://www.planalto.gov.br/ccivil_03/_ato20042006/2005/Lei/L11096.htm>. Acesso em: 14 set. 2011.

BRASIL. Sinopse estatística do censo da educação superior: 2003 a 2012. Brasília: MEC. Disponível em: http://inep.gov.br/sinopses-estatisticas-da-educacao-superior. Acesso em: 04 de abr. 2017.

BRASIL. MINISTÉRIO DA EDUCAÇÃO. PROUNI - Programa Universidade para Todos. 2012. Disponível em: <http://PROUNIportal.mec.gov.br/index.php?option=com content $\&$ view $=$ article \&id=124\&Itemid=140>. Acesso em: 21 ago. 2013.

BRASIL. Lei Federal $\mathbf{n}^{\circ}$ 5.172, 25 de outubro de 1966. Dispõe sobre o Sistema Tributário Nacional e institui normas gerais de direito tributário aplicáveis à União, Estados e Municípios. 1966. Disponível em http://www.planalto.gov.br/ccivil_03/leis/L5172.htm. Acesso em: 04 Out. 2017

CARVALHO, Cristina Helena Almeida de. Política de ensino superior e renúncia fiscal: da reforma universitária de 1968 ao PROUNI. In: ENCONTRO DA ANPED, 28., 2005, Caxambu/MG. Anais... Caxambu: Anped, 2005.

CARVALHO, Cristina Helena Almeida de. O PROUNI no Governo Lula e o jogo político em torno do acesso ao ensino superior. Educação \& Sociedade, Campinas/SP, v. 27, n. 96 Especial, p. 979-1000, out. 2006a. Disponível em:

<http://www.scielo.br/pdf/es/v27n96/a16v2796.pdf>. Acesso em: 10 set. 2012.

CARVALHO, Cristina Helena Almeida de. Política para o Ensino Superior no Brasil (1995-2006): ruptura e continuidade nas relações entre público e privado. Política de Educação Superior $\mathrm{n}^{\circ}$. 11. 2006b. Disponível em:

<http://webcache.googleusercontent.com/search?q=cache:0cKyw24nbiMJ:www.anped11.uerj .br/29/GT11-2337--Int.rtf+\&cd=1\&hl=pt-BR\&ct=clnk\&gl=br>. Acesso em: 10 out. 2013.

CARVALHO, Cristina Helena Almeida de. Agenda neoliberal e a política pública para o ensino superior nos anos 90. Diálogo Educacional, Curitiba/PR, v. 7, n. 21, p.83-101, maio/ago. 2007. Disponível em:

http://www2.pucpr.br/reol/pb/index.php/dialogo?dd1=1041\&dd99=view\&dd98=pb>. Acesso em: 30 abr. 2017.

CARVALHO, Cristina Helena Almeida de; LOPREATO, Francisco L. C. Finanças públicas, 
Programa Universidade para Todos (PROUNI): efeitos financeiros em uma instituição de educação superior privada

renúncia fiscal e o PROUNI no governo Lula. Impulso, Piracicaba/SP, v. 16, n. 40, p. 93-104, maio/ago. 2005.

CATANI Afrânio Mendes; HEY Ana Paula; GILIOLI Renato de Sousa Porto. PROUNI: democratização de acesso às Instituições de educação superior. Educar, Curitiba/PR, n. 28, p. 125-140, 2006. Disponível em: < http://www.scielo.br/scielo.php?pid=S0104-

40602006000200009\&script=sci_abstract\&tlng=pt>. Acesso em: 15 out. 2013.

CHAVES, Vera Lucia Jacob. Política de financiamento e a expansão da educação superior no Brasil: o público e o privado em questão. Educação Temática Digital, Campinas/SP, v. 17, n. 2, p. 427-441, 2015. Disponível em: <http://periodicos.sbu.unicamp.br/ojs/index.php/etd. 2015>. Acesso em: 24 abril 2017.

DOURADO, Luiz Fernandes. Reforma do Estado e políticas para a educação superior no Brasil nos anos 90. Educação \& Sociedade, Campinas/SP, v. 23, n. 80, p. 235-253, set. 2002. Disponível em: < http://www.scielo.br/pdf/es/v23n80/12931.pdf>. Acesso em: 28 abr.2017

DOURADO, Luiz Fernandes. Políticas e gestão da educação superior no Brasil: múltiplas regulações e controle. RBPAE, Goiânia/GO, v. 27, n.1, p. 53-65, jan./abr. 2011. Disponível em: <http://seer.ufrgs.br/rbpae/article/view/19967>. Acesso em: 28 abr. 2017.

DURHAM, Eunice R. O ensino superior no Brasil: público e privado. São Paulo: Núcleo de Pesquisas sobre o Ensino Superior da Universidade de São Paulo - NUPES, mar. 2003.

Disponível em: <http://nupps.usp.br/downloads/docs/dt0303.pdf>. Acesso em: 20 ago. 2013.

FOREQUE, Flávia. PROUNI rende isenção fiscal de R $\$ 4$ bi a faculdades privadas. Folha de S. Paulo, São Paulo, 4 ago. 2013. Disponível em:

<http://www1.folha.uol.com.br/cotidiano/2013/08/1321455-PROUNI-rende-isencao-fiscalde-r-4-bi-a-faculdades-privadas.shtml >. Acesso em: 20 ago. 2013.

MANCEBO, Denise. Universidade para todos: a privatização em questão. Pro-Posições, Campinas, v. 15, n. 3, p. 75-90, set./dez. 2004. Disponível em:

<https://periodicos.sbu.unicamp.br/ojs/index.php/proposic/article/view/8643795/11288>.

Acesso em: 23 ago. 2013

OLIVEIRA, Alcivam. A relação entre o Público e o Privado na Educação Superior no Brasil e o Programa Universidade Para Todos (PROUNI): acertos, ambiguidades e contradições. Tese (Doutorado em Educação) - Universidade Federal de Pernambuco, Recife, 2007.

OLIVEIRA, Cristiane Pereira Melo de. Programa Universidade para Todos: a percepção dos estudantes de uma universidade privada de São Paulo. Dissertação (Mestrado em Educação) - Universidade Cidade de São Paulo, São Paulo, 2012.

PARDO, Rosangela da Silva. Efeitos financeiros do Programa Universidade para Todos (PROUNI) em uma instituição de educação superior privada. Dissertação (Mestrado em Educação) - Universidade Cidade de São Paulo, São Paulo, 2013. Disponível em: https://siaa.cruzeirodosul.edu.br/consulta-dissertativa/ secure/wdiscon01/wdiscon01.jsf? codEmpr=10. Acesso em 04 de outubro de 2017.

PARDO, Rosangela; HAAS, Celia Maria. Financiamento da educação superior no Brasil: Os programas FIES, Reuni e Prouni em pesquisas da Capes. In: $11^{\circ}$ Encontro de Pesquisa em Educação da Região Sudeste, 10 a 15/10/2014, Universidade Federal de São João Del Rei. Culturas, Políticas e Práticas Educacionais e suas Relações com a Pesquisa, São João Del Rei/MG: Programa de Pós-Graduação em Processos Socioeducativos e Práticas Escolares / UFSJ, 2015. Volume II, pp 1-11. 
SAMPAIO, Helena. O setor privado de ensino superior no Brasil: continuidades e transformações. Ensino Superior UNICAMP, Campinas/SP, out. 2011. Disponível em: https://www.revistaensinosuperior.gr.unicamp.br/artigos/o-setor-privado-de-ensino-superiorno-brasil-continuidades-e-transformacoes. Acesso em: 24 abr. 2017.

SANTOS, Maria Rosimary Soares dos. Expansão e financiamento da educação superior privada em Minas Gerais. Anais do XXIV Seminário Nacional UNIVERSITAS/BR, 2016. Disponível em: http://www.ppe.uem.br/xxivuniversitas/anais/trabalhos/e_1/1-005.pdf. Acesso em 04 abr. 2017.

SGUISSARDI, Valdemar. A reforma universitária no Brasil 1995-2006: precária trajetória e incerto futuro. Educação \& Sociedade, Campinas/SP, v. 27, n. 96, p. 1021- 1056, out. 2006. Disponível em: <http://www.cedes.unicamp.br>. Acesso em: 20 ago. 2012.

SGUISSARDI, Valdemar. Modelo de expansão da educação superior no Brasil: predomínio privado/mercantil e desafios para a regulação e a formação universitária. Educação \&

Sociedade, Campinas/SP, v. 29, n. 105, p. 991-1022, set./dez. 2008. Disponível em: $<$ http://www.scielo.br/scielo.php?pid=S0101-

73302008000400004\&script=sci_abstract\&tlng=pt>. Acesso em: 24 abr. 2017

SGUISSARDI, Valdemar; SILVA JÚNIOR, João dos Reis. A educação superior privada no Brasil: novos traços de identidade. In: SGUISSARDI, Valdemar (Org.). Educação superior: velhos e novos desafios. São Paulo: Xamã, 2000. p. 155-178.

SGUISSARDI, Valdemar; SILVA JÚNIOR, João dos Reis. Educação superior: análise e perspectivas de pesquisa. São Paulo: Xamã, 2001.

SCHWARTZMAN, Jacques. Políticas de ensino superior no Brasil na década de 90. São Paulo: Núcleo de Pesquisas sobre Ensino Superior da Universidade de São Paulo - NUPES, 1996. Disponível em: <http://nupps.usp.br/downloads/docs/dt9603.pdf>. Acesso em: 24 abr. 2017.

Celia Maria Haas - Universidade Cidade de São Paulo São Paulo | SP | Brasil. Contato: celiahaas1@gmail.com

Rosangela da Silva Pardo - Universidade Nove de Julho São Paulo | SP | Brasil. Contato: rosangelapardo@gmail.com 